\title{
WEB 2.0: DESAFIO INSUPERÁVEL OU OPORTUNIDADE PARA A INCLUSÃO DIGITAL?
}

\author{
WEB 2.0: INSURMOUNTABLE CHALLENGE OR OPPORTUNITY FOR THE \\ DIGITAL INCLUSION?
}

\begin{abstract}
Mauro Marafiga Camozzato
Graduando em Direito na Universidade Federal de Santa Maria - UFSM. Habilitado em Mediação pela Universidad Nacional del Litoral - UNL (Argentina). Graduado em Ciência da computação pela Universidade de Passo Fundo - UPF. Pesquisador do Grupo de Pesquisa em Direito da Sociobiodiversidade - GPDS/UFSM.
\end{abstract}

\section{RESUMO}

Este artigo tem como objetivo abordar a problemática da exclusão digital sob o enfoque do analfabetismo funcional, salientando a importância da inclusão social efetiva como elemento importante na definição dessas terminologias. Também é objetivo do artigo observar esses conceitos quando relacionados com a aceleração das necessidades sociais e econômicas trazidas pela sociedade conectada em rede, notadamente após o advento da Web 2.0. Busca-se questionar - sem responder - se o cenário atual é de desafio desanimador ou de oportunidade para a inclusão digital. Para isso, são analisadas as conceituações trabalhadas antecipadamente, de "analfabetismo funcional" e de "exclusão digital", em comparação com as novas necessidades e oportunidades sociais surgidas a partir da conexão instantânea oferecida pelas redes sociais e plataformas de colaboração. Para fins de ilustração otimista, são apresentados alguns exemplos de iniciativas de inclusão digital em redes sociais inclusivas, as quais obtiveram resultados satisfatórios.

Palavras-chave: analfabetismo funcional; exclusão digital; inclusão digital; redes sociais inclusivas; Web 2.0.

\begin{abstract}
This work aims to approach the problem of digital divide from the standpoint of functional illiteracy, highlighting the importance of effective social inclusion as important element for the definition of these terminologies. Also aim of the paper is to observe these concepts as they relate the acceleration of social and economic needs brought about by the networked society, especially after the advent of Web 2.0 concept. The objective is to question if the current scenario is daunting challenge or opportunity to the digital inclusion. For this, we analyze the concepts worked in advance of "functional illiteracy" and "digital divide" in comparison with the new needs and social opportunities arising from the instant connection offered by social networking and collaboration platforms. For illustration purposes optimistic, we present some examples of digital inclusion initiatives in inclusive social networks, which obtained satisfactory results.
\end{abstract}

Keywords: digital divide; digital inclusion; inclusive social networks; functional illiteracy; Web 2.0.

\section{SUMÁRIO}

INTRODUÇAO; 1 UMA INTRODUÇÃO AO CONCEITO DE ANALFABETISMO FUNCIONAL; 2 INCLUSÃO DIGITAL E EXCLUSÃO DIGITAL; 3 O ADVENTO DA WEB 2.0 E AS OPORTUNIDADES PARA A INCLUSÃO DIGITAL; 4 REDES SOCIAIS INCLUSIVAS: DOIS PROJETOS QUE DERAM CERTO; 5 BREVES COMENTÁRIOS SOBRE POSTURAS POLÍTICAS BRASILEIRAS PARA A INCLUSÃO DIGITAL; CONCLUSÃO; REFERÊNCIAS. 


\section{INTRODUÇÃO}

A sociedade, conectada em rede, está sendo transformada. A Internet não é mais apenas um local para a troca de informações mas, principalmente, uma poderosa ferramenta para a conexão de pessoas. Paralelamente, milhões de indivíduos estão excluídos do acesso a tecnologias básicas e, mais ainda, do conhecimento mínimo necessário para utilizar essas tecnologias como ferramentas de efetiva inclusão social, democrática e econômica.

Nesse contexto, o objetivo desse trabalho é analisar a exclusão digital sob a ótica do analfabetismo funcional, fugindo da concepção reducionista do simples acesso físico aos computadores. Uma vez superada tal simplificação, a complexidade do tema será confrontada com a revolução tecnológica causada pelos ambientes digitais da Web 2.0, os quais provocaram uma aceleração sem precedentes nas relações interpessoais. Assim, pergunta-se: esse novo paradigma de interação social é um desafio insuperável para a inclusão digital ou é uma oportunidade? Sem responder a essa pergunta, são apresentados dois projetos de redes sociais inclusivas que trouxeram oportunidades para pessoas de baixa renda e com pouca familiaridade com a tecnologia.

Os métodos utilizados foram o investigativo e o dedutivo, através da pesquisa bibliográfica e da busca por informações na Internet que poderiam ser pertinentes ao trabalho.

Assim, os primeiros capítulos analisam as expressões "analfabetismo funcional" e o par de expressões indissociáveis “exclusão/inclusão digital”. O terceiro capítulo aborda a temática do advento da Web 2.0 e as implicações da aceleração nas relações sociais quanto ao tema, lançando-se o questionamento principal do trabalho. Por fim, o capítulo quatro apresenta exemplos de iniciativas de redes sociais inclusivas, antes das conclusões.

\section{UMA INTRODUÇÃO AO CONCEITO DE ANALFABETISMO FUNCIONAL}

Segundo Vera Massagão Ribeiro, o termo "analfabetismo funcional" foi utilizado originalmente pelo exército norte-americano durante a Segunda Guerra Mundial, significando a capacidade de entender instruções escritas necessárias para a realização de tarefas militares. Conforme a autora, hoje, nos Estados Unidos, o sentido mais corrente do termo referencia-o às "basic skills" (competências funcionais), sendo importante para essa abordagem o conceito 
sempre atualizado fornecido pelo programa de pesquisa chamado Adult Performance Level Project, desenvolvido na Universidade do Texas desde 1973:

Através de metodologias quantitativas e qualitativas, esse programa visa definir as competências funcionais necessárias ao desempenho satisfatório em contextos socioculturais determinados. Ao lado da leitura, da escrita e do cálculo, o programa considera como competências funcionais a linguagem oral, a informática, a resolução de problemas e as habilidades interpessoais aplicadas a contextos como a economia doméstica, a saúde, o trabalho, os recursos comunitários, as leis e o governo. ${ }^{1}$

Ribeiro informa também que a ampla disseminação do termo "analfabetismo funcional" se deve à Organização das Nações Unidas para a Educação, a Ciência e a Cultura (UNESCO), quando esta adotou a expressão com o objetivo de "padronizar as estatísticas educacionais e influenciar as políticas educativas dos países membros"2. Salienta-se que a própria Unesco, posteriormente, iria propor uma ampliação do qualitativo "funcional”:

[...] 0 qualitativo funcional insere a definição do alfabetismo na perspectiva do relativismo sociocultural. Tal definição já não visa limitar a competência ao seu nível mais simples (ler e escrever enunciados simples referidos à vida diária), mas abrigar graus e tipos diversos de habilidades, de acordo com as necessidades impostas pelos contextos econômicos, políticos ou socioculturais. ${ }^{3}$

A autora também atenta para o risco de essa definição ser interpretada pelo enfoque progressista/liberal, pela qual “[...] a funcionalidade da alfabetização dizia respeito, principalmente, à formação de mão-de-obra apta a adaptar-se às exigências da modernização econômica"4.

Superado esse risco, pode-se concluir que a expressão "analfabetismo funcional” busca evitar o reducionismo da palavra "analfabeto" ao significado simplista fornecido pelos dicionários, como o clássico Michaelis, que traz seguinte definição:

a.nal.fa.be.to

adj (gr analphábetos) 1 Que não sabe ler nem escrever. 2 Sem instrução primária. 3 Que é muito ignorante. sm 1 Indivíduo que ignora o alfabeto. 2

\footnotetext{
${ }_{1}^{1}$ RIBEIRO, Vera Masagão. Alfabetismo Funcional: Referências conceituais e metodológicas para a pesquisa. Revista Educação \& Sociedade, São Paulo, ano XVIII, n 60, dez. 1997. Disponível em <http://www.scielo.br/pdf/es/v18n60/v18n60a8.pdf>. Acesso em: 18 dez. 2012.

${ }^{2}$ Ibidem.

3 Ibidem.

${ }^{4}$ Ibidem.
} 
Indivíduo que não tem instrução primária. 3 Indivíduo muito ignorante. Antôn (acepção 3): culto, polido. ${ }^{5}$

Essa ampliação de significado entre as palavras "analfabetismo" e "analfabetismo funcional" é importante porque do significado simplista citado pelo dicionário poder-se-ia inferir que basta ao indivíduo saber ler e escrever para que possa ser considerado apto a desenvolver, com completude, suas relações interpessoais. Com base nesse significado, as políticas públicas para a erradicação do analfabetismo poderiam satisfazer-se em solucionar o problema da leitura e escrita sem, de fato, inserirem os indivíduos em um contexto que os permita desenvolverem-se na sociedade. Tais iniciativas podem ser consideradas, do ponto de vista da efetiva inclusão social, como meros paliativos, consentidos veladamente pela população.

Pedro Demo questiona se “[...] é isto inclusão social? Facilmente aceitamos como inclusão social a inclusão na margem. Os pobres estão dentro, mas dentro lá na margem, quase caindo fora do sistema. Continuam marginalizados. 0 que mudou foi a maquiagem da pobreza"6.

Esse conflito conceitual é particularmente importante para o Brasil uma vez que, segundo o Instituto Brasileiro de Geografia e Estatística (IBGE), o país tem alcançado índices cada vez maiores de alfabetização entre as crianças com 5 anos ou mais ${ }^{7}$. Tais informações estão disponíveis no sítio oficial do IBGE na Internet, o qual traz uma tabela informando que o percentual de indivíduos de 5 anos ou mais alfabetizados passou de 85,39, em 2001, para 90,17, em 2011, nunca decaindo nesse período ${ }^{8}$. A mesma página da Internet apresenta o conceito de alfabetização utilizado pelo Instituto: “Definição: alfabetizada: pessoa capaz de ler e escrever pelo menos um bilhete simples no idioma que conhece."

Já para o termo "analfabetismo funcional", o sítio oficial do IBGE traz outros números, porém o mesmo otimismo. As taxas caem ininterruptamente, de 27,3, em 2001, para 20,3, em

5 MICHAELIS. Dicionário de Português On-line. Disponivel em <http://michaelis.uol. com.br/ moderno/portugues/index.php?lingua=portugues-portugues\&palavra=analfabeto>. Acesso em: 18 dez. 2012.

${ }^{6}$ DEMO, Pedro. Inclusão digital - cada vez mais no centro da inclusão social. Revista Inclusão Social, Brasília, v. 1, n. 1, p 36-38, out./mar., 2005. Disponível em <http://revista.ibict.br/inclusao/index.php/ inclusao/article/view/4>. Acesso em: $18 \mathrm{dez} .2012$.

7 IBGE - Instituto Brasileiro de Geografia e Estatística. Pessoas de 5 anos ou mais de idade, por alfabetização. Disponível em <http://seriesestatisticas.ibge.gov.br/series.aspx?vcodigo= PD319\& sv=8\&t =pessoas-5-anos-mais-idade-alfabetizacao>. Acesso em $18 \mathrm{dez} .2012$.

8 Ibidem.

${ }^{9}$ Ibidem. 
2009, ano mais recente registrado ${ }^{10}$. Por oportuno, transcreve-se a definição de analfabetismo funcional informada no referido sítio: “Definição: taxa de analfabetismo funcional: porcentagem de pessoas de uma determinada faixa etária que tem escolaridade de até 3 anos de estudo em relação ao total de pessoas na mesma faixa etária."

Bruno Pires Malaquias afirma que o IBGE passou a apresentar a estatística de “analfabetismo funcional” por recomendação da Unesco, porém, questiona o critério adotado, já que toma por base não a auto-avaliação dos respondentes e sim, o número de séries escolares concluídas:

Pelo critério adotado, são analfabetas funcionais as pessoas com menos de quatro anos de escolaridade. [...] é quase um exercício de imaginação admitir que uma pessoa com apenas parcos quatro anos de vida escolar possa se inserir numa sociedade regida pelas tecnologias de informação. Informação está diretamente ligada à educação, essa garantida pela vigente Constituição brasileira. ${ }^{11}$

Além da crítica supracitada, os números dos últimos dois anos mantiveram-se estabilizados, segundo o jornal Último Segundo, vinculado ao Portal IG ${ }^{12}$. O periódico digital, na data de 21 de setembro de 2012, apresentou reportagem sobre o assunto, sob a Manchete "Taxa de analfabetismo funcional fica estagnada entre 2009 e 2011":

[...] Embora o número de analfabetos tenha diminuído de 2009 para 2011 no Brasil, o percentual de pessoas consideradas analfabetas funcionais permaneceu o mesmo no período. Não conseguem participar de todas as atividades em que a alfabetização é necessária $20,4 \%$ dos brasileiros com mais de 15 anos, o mesmo índice observado em 2009 pela Pesquisa Nacional por Amostra de Domicílios (Pnad) do Instituto Brasileiro de Geografia e Estatística (IBGE), cujos novos dados foram divulgados nesta sexta-feira, dia $21 .^{13}$

Curiosamente, apesar da fragilidade da definição utilizada pelo IBGE, o Instituto não apresenta as estatísticas de “estabilização" do índice (dados entre 2009 e 2011), que o jornal garante existir. Sem maiores aprofundamentos nessa discussão, fica a sugestão de uma análise mais minuciosa acerca da transparência do Portal do IBGE, sua independência política em

\footnotetext{
${ }^{10}$ IBGE - Instituto Brasileiro de Geografia e Estatística. Taxa de analfabetismo funcional. Disponível em <http://seriesestatisticas.ibge.gov.br/series.aspx?vcodigo=PD384\&t=taxa-analfabetismo-funcional> . Acesso em $18 \mathrm{dez} .2012$.

11 MALAQUIAS, Bruno Pires. O Analfabetismo Digital. In: IBDI - Instituto Brasileiro de Direito da Informática. Disponível em <http://www.ibdi.org.br/site/artigos.php?id=159>. Acesso em: 18 dez. 2012.

12 KLIX, Tatiana. Taxa de analfabetismo funcional fica estagnada entre 2009 e 2011. Último Segundo, São Paulo, 21 set. 2012. Disponível em <http://ultimosegundo.ig.com.br/educacao/2012-09-21/taxa-deanalfabetismo-funcional-fica-estagnada-entre-2009-e-2011.html >. Acesso em 18 dez. 2012.

${ }^{13}$ Ibidem.
} 
relação ao governo e, também, quanto à significância e utilidade dos dados apresentados, em confrontação com a realidade social brasileira.

\section{INCLUSÃO DIGITAL E EXCLUSÃO DIGITAL}

Se a definição de "analfabetismo funcional", enredada de vieses sociais, políticos e econômicos, não é tarefa simples, também a conceituação de "exclusão digital" não deve ser obtida de forma superficial, sem uma análise mais apurada dos elementos que the tangenciam.

Victor Hugo Gonçalves, em importante trabalho sobre o tema, não dissocia as expressões “inclusão digital” e "exclusão digital”, o que justifica a aplicação de um ou outro termo em trabalhos que versem sobre o assunto:

[...] Onde há uma necessidade de inclusão há o reconhecimento implícito da exclusão. É no reconhecimento deste duplo conceitual nas práticas históricas, sociais, econômicas e culturais das tecnologias de informação e comunicação, que surgem os questionamentos, os desafios, as ações, as omissões, as lutas, os conflitos. $^{14}$

Nesse contexto, o autor sugere uma desconstrução e reconstrução histórico-social do termo, lembrando que "sempre houve formas de transmissão de informações e comunicação"15. Dessa maneira, os valores estão todos intrinsecamente ligados ao tempo historicamente vivido:

As teias das relações vão exigindo, a velhos e novos problemas, soluções originais e que enfrentem uma determinada situação conflituosa ou de desconforto. A cada novo desafio existe uma valoração cultural da retenção daquele novo conhecimento. Assim, esta necessidade gera um novo sentido à realidade e à atividade do ser humano. Daí que toda a necessidade, invariavelmente, e percebida coletivamente e elevada a item básico social no seu uso diuturno. ${ }^{16}$

Dessa maneira, a inclusão digital seria uma apropriação do conceito de inclusão social, construído numa leitura, a partir dos anos de 1960 e 1970, da Declaração Universal dos Direitos Humanos de 1948. A partir da difusão da globalização econômica nas década de 1980 e 1990, o clamor por inclusão social teria se intensificado, tomando diferentes formas:

${ }^{14}$ GONÇALVES, Victor Hugo. Inclusão digital como direito fundamental. 2011. 135 f. Dissertação (Mestrado em Direito) - Universidade de São Paulo, São Paulo, 2011, p. 35.

${ }^{15}$ Ibidem, p. 22.

${ }^{16}$ Ibidem, p. 24. 
0 discurso da inclusão social tornou-se vivo e atuante em todos os níveis e extratos das sociedades do mundo todo. 0 discurso da inclusão social foi apreendido e apropriado por negros, índios, pessoas com deficiência, mulheres, homossexuais etc., enfim, todos os excluídos por práticas sociais, históricas, econômicas e culturais. Foi dentro deste contexto de contestação a práticas excludentes estabelecidas que surgiu a apropriação do termo inclusão para designar a luta pelo acesso as TIC como meio de superação das desigualdades. A esta luta foi atribuído o nome de inclusão digital. ${ }^{17}$

De passagem, o autor lembra que a palavra "digital" foi apreendida e apropriada diferentemente do seu significado original (de relativo a dedos e a dígito), podendo levar a uma perspectiva de inserção somente à tecnologia em detrimento de novas possibilidades de ação humana. No entanto, essa discussão não tem relevância, devido ao importante contexto hodiernamente atribuído ao termo:

[...] a combinação de palavras que formam a expressão "inclusão digital” pode não ser a mais apropriada, academicamente, mas deriva de um ambiente forte de lutas sociais. [...] Portanto, a expressão "inclusão digital" tem como eixo central a busca pela superação das barreiras e obstáculos que são instituídos nas relações sociais e que acabam por gerar as exclusões. ${ }^{18}$

Enfim, do exposto sobre o trabalho de Victor Hugo Gonçalves, conclui-se que a exclusão e a inclusão digitais dizem respeito a uma problemática mais profunda e complexa do que simplesmente garantir o acesso de todos à tecnologia. De fato, a nada serve uma política que possa fornecer materialmente o equipamento eletrônico, sem a devida instrução para que o indivíduo possa utilizá-lo de forma a ser inserido na sociedade.

Conforme Rondelli, "Dizer que inclusão digital é somente oferecer computadores seria análogo a afirmar que as salas de aula, cadeiras e quadro negro garantiriam a escolarização e o aprendizado dos alunos" 19 .

No mesmo sentido, Almeida e De Paula asseveram que a divulgação de doação de computadores como solução para o problema da exclusão digital não é suficiente: “[...] Não basta mostrar às pessoas as tecnologias, é necessário fazê-las entender de que forma as mesmas podem contribuir para a execução de tarefas, atividades e incrementarem o capital

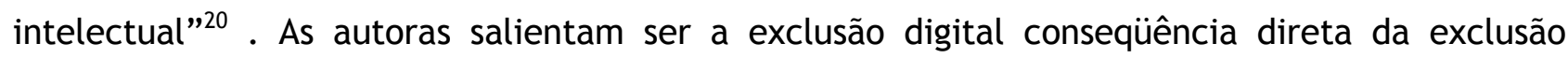

\footnotetext{
${ }^{17}$ Ibidem, p. 32.

${ }^{18}$ Ibidem, p. 33.

${ }^{19}$ RONDELLI, Elizabeth. Quatro passo para a inclusão digital. Revista Sete Pontos, Rio de Janeiro, Ano 1, n. 5, 2003. Disponível em <http://www.comunicacao.pro.br/setepontos/5/4passos.htm>. Acesso em: 18 dez. 2012.

${ }^{20}$ ALMEIDA, Lilia Bilati; DE PAULA, Luiza Gonçalves. O Retrato da Exclusão Digital na Sociedade Brasileira. Revista de Gestão da Tecnologia e Sistemas de Informação, Volta Redonda, RJ, v. 2, n. 1, 2005, pp. 55-
} 
social, e que o acesso àquela passa, necessariamente, pela inclusão nesta. Pela clareza do exposto no seu trabalho, oportuna a transcrição do trecho referido:

A exclusão sócio-econômica desencadeia a exclusão digital, ao mesmo tempo que a exclusão digital aprofunda a exclusão sócio-econômica. A inclusão digital deveria ser fruto de uma política pública com destinação orçamentária a fim de que ações promovam a inclusão e equiparação de oportunidades a todos os cidadãos. Neste contexto, é preciso levar em conta indivíduos com baixa escolaridade, baixa renda, limitações físicas e etárias. Na sociedade em que vivemos atualmente, uma pessoa sem conhecimentos em informática, muitas vezes é tida como desqualificada para trabalhar, visto que mesmo nas pequenas empresas ou escritórios os sistemas de informação estão presentes. Em conseqüência, gera-se baixa renda e desemprego. Com isso, o ciclo de pobreza e fome se torna mais intenso, havendo então, o desaquecimento da economia e os conseqüentes abalos diante dos mercados exteriores concorrentes, sem falar nos agravantes internos, como a proliferação de favelas, o aumento da violência e a elevação dos preços de mercado. A exclusão social e a exclusão digital são mutuamente causa e conseqüência. cidadãos que se enquadram em um ou mais tipos de exclusão social vistos anteriormente, podem ser inibidos de acompanharem a evolução tecnológica, passando a condição de integrantes da exclusão digital. Em contrapartida, cidadãos excluídos digitalmente por falta de empenho ou por opção própria, passam a fazer parte de um ou mais tipos de exclusão social. ${ }^{21}$

No trecho citado, salienta-se a preocupação das autoras com o ciclo de pobreza mantido pelo acréscimo constante de novas necessidades tecnológicas, ou seja, se o tratamento igualitário aos desiguais não é capaz de eliminar desigualdades, uma injustiça ainda maior será limitar a alguns - e não a outros, o acesso ao ferramental básico para a plenitude da cidadania. $\mathrm{E}$ esse ferramental deve abarcar, principalmente, o conhecimento técnico para a utilização efetiva das tecnologias.

Bernardo Sorj compartilha dessa opinião, afirmando que a exclusão digital possui forte correlação com as outras formas de desigualdade social, completando ao dizer que essa desigualdade também é medida pela capacidade de utilização das tecnologias:

[...] A desigualdade social no campo das comunicações, na sociedade moderna de consumo de massas, não se expressa somente no acesso ao bem material rádio, telefone, televisão, Internet -, mas também na capacidade do usuário de retirar, a partir de sua capacitação intelectual e profissional, o máximo proveito das potencialidades oferecidas por cada instrumento de comunicação e informação. ${ }^{22}$

67. Disponível em <http://www.revistasusp.sibi.usp.br/scielo.php?pid=S1807-17752005000100005 Escript=sci_arttext>. Acesso em: $18 \mathrm{dez} .2012$, p. 60.

${ }^{21}$ Ibidem, p. 59.

${ }^{22}$ SORJ, Bernardo. Brasil@povo.com. A luta contra a desigualdade na Sociedade da Informação. Rio de Janeiro: Zahar, 2003, p. 58. 
No entanto, o autor observa que em situações de crescimento econômico, a diminuição da pobreza não necessariamente indica uma diminuição das desigualdades sociais:

[...] Em situações de crescimento econômico, é possível diminuir a pobreza (a população que se encontra abaixo do que é considerado o mínimo necessário para viver numa sociedade dada) e, ao mesmo tempo, aumentar a desigualdade social. A luta contra a desigualdade e a contra a pobreza apresentam, portanto, superposições, mas não são sinônimas. ${ }^{23}$

Infelizmente, esse é um aspecto da sociedade de consumo globalizada difícil de ser confrontado. Ao que parece, deve-se tomar um extremo cuidado na análise de políticas públicas efetivas de inclusão digital, sob pena de mercantilização do conceito, fornecendo-se aparatos tecnológicos subutilizados, em um comércio de transferência de recursos entre governos e grandes empresas de tecnologia, agravando-se a problemática da exclusão digital.

Esse risco ocorre porque o desenvolvimento tecnológico acelerado favorece, por evidente, aqueles que possuem capacidade de adquiri-lo. Bernando Sorj e Luís Eduardo Guedes realizaram uma pesquisa nas comunidades de baixa renda do município do Rio de Janeiro e indicam que

[...] embora a maior parte da bibliografia sobre exclusão digital produzida pelas organizações internacionais enfatize o potencial das TICs para reduzir a pobreza e a desigualdade, na prática a dinâmica social funciona em sentido inverso: aumentam a exclusão e a desigualdade sociais. A universalização do acesso é antes de tudo um instrumento para diminuir os danos sociais do ponto de vista da luta contra a desigualdade.

[...]

A introdução de novos produtos, que passam a ser indicativos de uma condição de vida "civilizada" (seja telefone, eletricidade, geladeira, rádio ou TV), aumenta o patamar abaixo do qual uma pessoa ou família é considerada pobre.

[...]

Em ambos os casos, os novos produtos TICs aumentam, em princípio, a pobreza e a exclusão digital. ${ }^{24}$

Por fim, Sorj complementa que a exclusão digital depende de cinco fatores que determinam a maior ou menor universalização dos sistemas telemáticos: 1) a existência de infraestruturas físicas de transmissão; 2) a disponibilidade de equipamento/conexão de acesso (computador, modem, linha de acesso); 3) treinamento no uso dos instrumentos do computador e da Internet; 4) capacitação intelectual e inserção social do usuário, produto da profissão, do

\footnotetext{
${ }^{23}$ Ibidem, p. 61.

${ }^{24}$ SORJ, Bernardo, GUEDES, Luiz Eduardo. Exclusão Digital. Problemas conceituais, evidências empíricas e políticas públicas. Revista Novos Estudos, n. 72, pp. 101-117, 2005, p. 102.
} 
nível educacional e intelectual e de sua rede social, que determina o aproveitamento efetivo da informação e das necessidades de comunicação pela Internet; 5) a produção e uso de conteúdos específicos adequados às necessidades dos diversos segmentos da população. ${ }^{25}$

Segundo o autor, "enquanto os primeiros dois critérios se referem a dimensões passivas do acesso à Internet, as três últimas definem o potencial de apropriação ativa"26. Isso significa que os dois primeiros critérios podem ser resolvidos através de políticas que possibilitem o acesso técnico ao maquinário tecnológico, porém, é em relação aos outros três critérios que se insere o conceito de "inclusão digital" como acessibilidade à participação democrática e à inclusão social. E é nesse nível que reside a problemática do advento da Web 2.0, a qual potencializou a utilização da Internet para a instantaneidade das relações sociais.

\section{O ADVENTO DA WEB 2.0 E AS OPORTUNIDADES PARA A INCLUSÃO DIGITAL}

De acordo com o exposto nos capítulos anteriores, pode-se inferir que o desenvolvimento da tecnologia, sem o acompanhamento da devida inclusão social, resulta no agravamento das desigualdades sociais e da exclusão digital. Além disso, esse processo é cruelmente cíclico, pois a população marginalizada está cada vez mais longe de obter o conhecimento mínimo para exercer sua cidadania, e assim, suporta cada vez mais a opressão econômica, tendo como conseqüência um maior afastamento de aptidões para operar a tecnologia, reiniciando-se o ciclo, e assim por diante.

Diante de tal contexto, cabe a pergunta: o advento da Web 2.0 é apenas mais um ingrediente desse ciclo interminável? Ou pode ser considerado como uma revolução que transformará substancialmente as relações sociais, de forma a produzir um esmagador abismo social sem precedentes?

Ou, quem sabe, não seria, essa tecnologia, a esperança para a implementação de políticas públicas efetivas de inclusão digital e, consequentemente, social?

A expressão "Web 2.0" é utilizada para descrever uma espécie de segunda geração da World Wide Web: o início de uma tendência que reforça o conceito de troca de informações e

\footnotetext{
${ }^{25}$ SORJ, Bernardo. Brasil@povo.com. A luta contra a desigualdade na Sociedade da Informação. Rio de Janeiro: Zahar, 2003, p. 61.

${ }^{26}$ Ibidem, p. 61.
} 
colaboração dos internautas. O termo não se refere à atualização nas suas especificações técnicas, mas uma mudança na forma como ela é encarada por usuários e desenvolvedores. 0 criador do termo, Tim O'Reilly, prefere não fixar uma definição para ele, mas o explica em um artigo de cinco páginas, disponível na Internet ${ }^{27}$.

Alguns especialistas em tecnologia, como Tim Berners-Lee, o inventor da World Wide Web (www), alegam que o termo carece de sentido, pois a Web 2.0 utiliza muitos componentes tecnológicos criados antes mesmo do surgimento da Web. Alguns críticos do termo afirmam também que esta é apenas uma jogada de marketing (buzzword). A Web 2.0 é alvo de discussão entre alguns entusiastas, tecnófilos e tecnófobos ${ }^{28}$.

Segundo Erm Ayara e Sabg Vidotti, é comum a confusão entre Internet e Word Wide Web:

\begin{abstract}
A World Wide Web, Web ou www é definida pelo seu idealizador, o físico inglês Tim Berners-Lee (1996), como o universo da informação acessível na rede global. Ela é um espaço abstrato povoado, principalmente, por páginas interconectadas de texto, imagens e animações, com ocasionais sons, mundos tridimensionais e vídeos com os quais os usuários podem interagir. É comum que as pessoas ainda confundam Web com Internet. Berners-Lee $(2001$, p.5) fala sobre a diferença em sua página no site da W3C: "A Web é um espaço de informação abstrato (imaginário). Na Internet você encontra computadores - na Web, você encontra documentos, sons, vídeos,... informação. Na Internet, as conexões são cabos entre computadores; na Web, as conexões são os links de hipertextos. A Web existe devido a programas que se comunicam entre computadores na Internet. A Web não poderia ser criada sem a Internet. A Web tornou a rede útil porque as pessoas estão realmente interessadas em informação (para não citar conhecimento e sabedoria!) e realmente não querem saber sobre computadores e cabos $^{29}$.
\end{abstract}

Superadas as diferenças entre Internet, Word Wide Web (Web) e Web 2.0, pode-se afirmar que esta última tem um potencial diferenciado para revolucionar as relações humanas quando se observa o poder das ferramentas wiki e das plataformas de colaboração, que permitem a reconstrução e auto-regulação constante da informação em tempo real. Essa nova percepção provocou uma transformação no paradigma sobre a disseminação da informação em redes, ao ponto de se poder dizer que se está iniciando uma nova era para a humanidade. Isso porque, pela primeira vez, a tecnologia disponibiliza um espaço para a resolução de problemas

${ }^{27}$ O'REILLY, Tim. What Is Web 2.0. Design Patterns and Business Models for the Next Generation of Software. 30 set. 2005. Disponível em <http://oreilly.com/Web2/ archive/what-is-Web-20.html>. Acesso em 18 dez. 2012.

${ }^{28}$ WIKIPEDIA, Web 2.0. Disponível em <http://pt.wikipedia.org/wiki/Web_2.0>. Acesso em: 18 dez. 2012.

${ }^{29}$ AYARA, Erm.; VIDOTTI, Sabg. Ambientes Informacionais Digitais. In Criação, proteção e uso legal de informação em ambientes da Word Wide Web. São Paulo: UNESP, 2010. 
que permite a interconexão de qualquer interessado em compartilhar seu conhecimento, de forma instantânea, voluntária e sem custos. 0 resultado disso é união de esforços cujo potencial construtivo é inédito na história da civilização, momento em que a humanidade se une, sistêmica e organicamente, em prol da resolução de um problema em comum.

Esse novo direcionamento tecnológico está transformando todas as relações sociais, com grande impacto na economia, na política, nos costumes, etc. Não há dúvidas de que a tecnologia das redes se desenvolve e interconecta as pessoas em progressão exponencial. Então, até quando se poderá prescindir da tecnologia em rede para a implantação e execução de políticas públicas? Se a execução de tais políticas está fortemente vinculada à participação democrática e política de todos os membros da sociedade, então interessa, para a compreensão dessa problemática, o estudo do exercício da cidadania através da participação em rede por meio das mídias sociais.

Segundo Castells, "a política da mídia não se aplica a todas as formas de fazer política, mas todas as formas de política têm necessariamente de passar pela mídia para influenciar o processo decisório" 30 .

Por tudo isso, não é possível imaginar que essa tendência tecnológica não terá uma grande influência no comportamento humano. A internet não é um mundo paralelo, sem identidade com o mundo real. Ela é o mundo real - em um outro ambiente, com símbolos diferentes, porém que representam - e afetam - o mundo real. Segundo Pierre Levy, o virtual é tão somente um real "não presencial", porém existente e produz efeitos. Levy assevera, inclusive, que o virtual em nada tem a ver com o advento da internet e sim, acompanha desde sempre a condição humana, como, por exemplo: as leis, as línguas, os meios de comunicação ou de transporte etc. ${ }^{31}$.

De todo o exposto, pode-se se concluir que a parcela da população com acesso às redes sociais está vivendo em um contexto de participação democrática e construção de cidadania. E a outra parcela? Será que o simples acesso à tecnologia nas escolas ou em lan-houses pode ser o suficiente para inserir o indivíduo nessa participação social?

Não se tem, neste trabalho, a ambição de responder a essa pergunta, mas há motivos para otimismo. A conexão da comunidade em rede pode, muito mais do que em outras épocas,

\footnotetext{
${ }^{30}$ CASTELLS, Manuel. 0 poder da identidade. 5. ed. Tradução de Klauss Brandini Gerhardt. São Paulo: Paz e Terra, 2006, p. 374.

${ }^{31}$ LEVY, Pierre. 0 que é Virtual?. São Paulo, editora 34, 1996.
} 
trazer a inclusão digital - na acepção sociológica do termo, pois tem o poder de conectar o indivíduo diretamente com outros indivíduos que compartilham do mesmo interesse.

Em outras palavras, se antes do advento da Web 2.0, o acesso à tecnologia poderia significar uma interação pessoa-máquina para a realização individual de tarefas ou trabalho, após essa revolução, inclusão digital é aquela que propicia a interação pessoa-pessoa(s) através de máquinas. Essa nova concepção facilitaria consideravelmente a concentração de esforços entre os indivíduos que compartilham do mesmo interesse, em um sistema de colaboração mútua de participação democrática e social.

Nesse novo contexto, com otimismo, poder-se-ia até mesmo imaginar a existência de participação democrática por meio da inclusão digital sem o acesso direto aos computadores, como na hipótese de interconexão entre líderes locais para compartilhamento de informação, alinhamento de ações e fortalecimento político.

No capítulo seguinte, serão apresentados, exemplificativamente, dois projetos bemsucedidos de inclusão social através de redes sociais inclusivas, sem a participação direta da administração pública.

\section{REDES SOCIAIS INCLUSIVAS: DOIS PROJETOS QUE DERAM CERTO}

O objetivo deste capítulo é apresentar dois projetos de inclusão social que obtiveram resultados satisfatórios através da implementação de redes sociais inclusivas. 0 primeiro deles é vinculado à Fundação de Amparo à Pesquisa de São Paulo (FAPESP). O segundo é iniciativa de graduandos de Ciência da Computação-Licenciatura da Unisalle-Canoas/RS.

O projeto da FAPESP, nomeado Projeto e-Cidadania, é uma nova proposta de rede social on-line, em desenvolvimento no âmbito do instituto Virtual de Pesquisas FAPESP-Microsoft Research. O objetivo principal foi considerar a diversidade de habilidades e competências da população para motivar e viabilizar a participação dos usuários no processo de conhecimento e decisão sobre seu uso:

Uma vez identificadas as barreiras que impedem o acesso e uso desses sistemas pelos cidadãos brasileiros, pode-se propor diretrizes que reorientem o design de sistemas de redes sociais de forma contextualizada com nosso cenário sociodemográfico.

[...]

Em conjunto com artefatos de Semiótica Organizacional - disciplina em que são consideradas regularidades da percepção, do comportamento, de crenças e de 
ISSN 1981-3694

(DOI) $10.5902 / 198136947519$

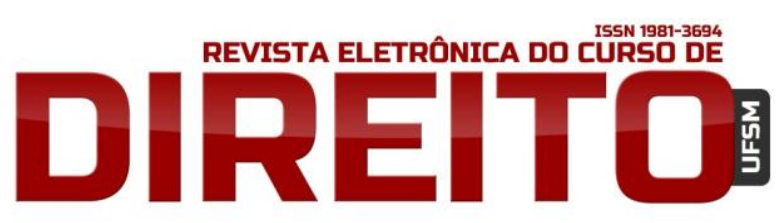

WEB 2.0: DESAFIO INSUPERÁVEL OU OPORTUNIDADE PARA A INCLUSÃO DIGITAL ?

valores - o grupo de pesquisa fez uso de técnicas e métodos do Design Participativo (DP), cujas práticas promovem a participação ativa dos usuários no processo de desenvolvimento das soluções. ${ }^{32}$

O diferencial do projeto foi a aposta no design para a familiarização dos usuários com os recursos hipermidiáticos - recursos computacionais interativos de interface do operador com textos, vídeos e sons. Assim, trabalhou-se com os usuários para que eles construíssem juntos os recursos computacionais, os quais, dessa forma, teriam facilidade de operar. Uma vez concluída a plataforma, os usuários, com idades entre 40 a 72 anos, desenvolveram sites, blogs, e compartilharam informações construtivas como "leitura e interpretação", "aplicação de lantejoulas”, “crochê”, “criação de anúncios” etc. O resultado foi animador, pois os usuários ficaram muito satisfeitos com a possibilidade de ensinar e aprender através da rede. A conclusão está em um trabalho publicado:

Os resultados mostram que é possível promover a aprendizagem e o domínio
criativo dos recursos hipermidiáticos por pessoas que não estavam familiarizados
com essas tecnologias. Elas foram capazes de selecionar e organizar
informações, gerar conhecimentos e estabelecer relações de interesse e laços
de amizade construídos entre os participantes. Segundo, mostrar que a
utilização de tecnologias por pessoas digitalmente excluídas deve estar atrelada
à disponibilização e acesso aos recursos tecnológicos e, também, a uma
proposta metodológica que considere as particularidades e especificidades tanto
dos usuários quanto da realidade na qual se encontram inseridos. ${ }^{33}$

O segundo projeto escolhido como exemplo é gaúcho. É a experiência de construção de um ambiente colaborativo de aprendizagem nas Escolas Municipais de Sapucaia do Sul. Com o uso de ferramentas wiki - mais especificadamente, a ferramenta Wikispaces ${ }^{34}$, as escolas participantes desenvolveram ambientes com vários projetos integrados ao ambiente central, enquanto que este serviu de âncora aos ambientes desenvolvidos em todas as escolas. 0 uso de blogs e wikis foram adotados "por serem tecnologias com suporte colaborativo que estimulam a iniciativa, a curiosidade, a descoberta, o reinventar e o prazer de aprender e estudar

\footnotetext{
32 MANGINI, Jussara. Redes Sociais mais inclusivas. In: Agência FAPESP. Disponível em <http://agencia.fapesp.br/10806>. Acesso em: $18 \mathrm{dez} .2012$.

${ }_{33}$ RODRIGUEZ, Carla Lopes, VALENTE, José Armando. Apropriação de Recursos Hipermidiáticos em Rede Social Inclusiva: elementos favoráveis à aprendizagem e à inclusão digital. Revista Digital La Educ@ción, n. 145, mai., 2011. Disponível em <http://www.educoas.org/portal/La_Educacion_Digital/laeducacion _145/studies/EyEP_josevalente_ES.pdf>. Acesso em: $18 \mathrm{dez} .2012$.

${ }_{34}$ WIKISPACES - Site para hospedagem gratuita de Wikis. Disponível em < http://www.wikispaces.com>. Acesso em: $18 \mathrm{dez} .2012$.
} 
cooperativamente. Um aprender que implica interagir, potencializando assim os ambientes de aprendizagem"35.

O ambiente virtual faz parte de uma proposta de trabalho de conclusão do curso de Computação-Licenciatura da Unilasalle, especificadamente voltado à aprendizagem, o qual trouxe conclusões interessantes no que concerne ao comportamento dos alunos envolvidos:

[...] Percebemos uma mudança de postura em relação aos processos de colaboração e cooperação, pois em um primeiro momento alguns alunos apresentaram uma certa resistência, demonstrando sentimento de posse em relação ao seu texto (histórias, poesias, pesquisas, etc.) e a dificuldade em trabalhar com o coletivo, até porque isto reflete a sociedade individualista em que vivemos. No entanto, na medida em que foram percebendo que a colaboração dos seus pares contribuía para o enriquecimento de suas produções, motivaram-se tanto para colaborar com o 'outro' como para aceitar as idéias dos colegas, tornando-se co-autores do processo de aprendizagem.

[...]

Como a Web 2.0 pode ser definida pela característica da comunicação em duas direções, ou seja, colaboração e ler/escrever, em relação à produção textual, também percebemos uma preocupação maior com a ortografia, pois não queriam "escrever errado em páginas da Internet" (palavras dos próprios alunos). Alguns alunos levavam dicionários para o laboratório de informática, para consultar em momentos de dúvidas, assim como perguntavam para os professores e colegas. Estes 'erros ortográficos' os levaram a constante depuração do pensamento, a construir novas hipóteses e a se apropriar de um novo vocabulário.

Também percebemos que os alunos ficavam orgulhosos de ler suas próprias contribuições e a dos colegas, muitos perguntavam até mesmo se poderiam mostrar aos pais em casa (pela internet). Isto demonstrou que este trabalho realizado com wiki transcendeu as construções cognitivas, contribuindo também para a emergência de questões sócio-afetivas dos alunos, neste caso, elevando a auto-estima. $^{36}$

Esses dois projetos de aplicação de redes sociais inclusivas são exemplos de iniciativas que abordaram a inclusão digital com a finalidade da inclusão social. Em ambos os casos, os organizadores dos projetos não ignoraram a realidade sócioeconômica dos participantes envolvidos. Ao invés disso, buscaram mecanismos em outras áreas do conhecimento diversas da computação, tais como design e semiótica, com o objetivo de possibilitar à população o acesso ao ferramental tecnológico.

\footnotetext{
${ }_{35}$ MANTOVANI, Ana Margô, VIANNA, Cristiane de Carvalho. Construção Colaborativa de Ambiente de Aprendizagem com o uso de Wiki. In: Seminário de Informática - RS (SEMINFO RS'2008). Torres, 14 a 16 de novembro de 2008, 2008, p. 1. Disponível em <http://www.seminfo.com.br/anais/2008/pdfs/ seminfo/3-50748.pdf>. Acesso em : 18 dez. 2012.

${ }^{36}$ Ibidem, p. 6
} 
ISSN 1981-3694

(DOI) $10.5902 / 198136947519$

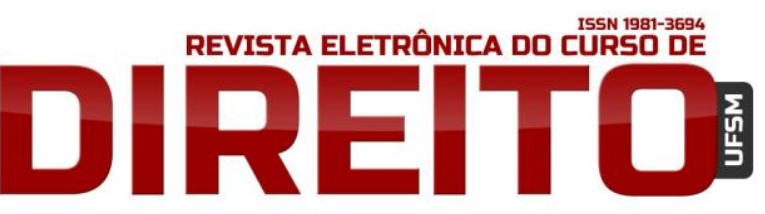

WEB 2.0: DESAFIO INSUPERÁVEL OU OPORTUNIDADE PARA A INCLUSÃO DIGITAL ?

O desenvolvimento desses projetos foi possível graças à flexibilidade do modelo da Web 2.0 que através de recursos de hipermídia - reunião de várias mídias em um suporte computacional - permite a "navegação" interativa entre recursos visuais, textuais e de áudio, por meio de comandos físicos, de voz ou até mesmo com um simples olhar para determinado ponto da tela do computador. Lançando mão dessas ferramentas, os projetos apresentados não apenas aproximaram os usuários da tecnologia como também proporcionaram a eles a utilização desse maquinário para a construção do conhecimento e da interação social, obtendo como resultado final um acréscimo na satisfação pessoal e na auto-estima.

\section{CONCLUSÃO}

$\mathrm{Na}$ primeira parte deste trabalho buscou-se conceituar as expressões "analfabetismo funcional" e "exclusão digital" sob um viés cidadão, ou seja, na concepção de "alfabetizado funcional" - ou "incluído digitalmente" - como aquele indivíduo capaz de desenvolver-se no tecido social, com conhecimento das ferramentas tecnológicas e de signo para exercer sua cidadania. Concluiu-se que é possível, sim, definir tais terminologias com base em uma teoria conceitual inclusiva.

Já a segunda parte do trabalho procurou apresentar o conceito de Web 2.0, e confrontar a problemática das redes sociais e sua avassaladora velocidade com a exclusão digital, lançando a pergunta: essa revolução criará um abismo social ou poderá ser vista com uma oportunidade para o desenvolvimento de tecnologias de inclusão social? A conclusão não responde a esta pergunta, mas lança um olhar otimista sobre o assunto, uma vez que essa revolução tem a novidade de aproximar as pessoas com interesses em comum e, portanto, é possível, através de políticas sérias, tirar proveito desses ambientes informacionais para efetivar-se a aproximação dos indivíduos, desde que se consiga escapar da armadilha da mercantilização da inclusão digital, com o simples fornecimento de máquinas para a população marginal.

Durante as pesquisas realizadas, constatou-se a fragilidade dos dados fornecidos pelo sítio do IBGE e principalmente, a superficialidade dos conceitos adotados para "analfabetismo" e “analfabetismo digital”, muito aquém do conceito considerado como realmente inclusivo constatado nesse trabalho. Sugere-se o debate acerca da eficácia de políticas públicas de erradicação do analfabetismo baseadas nesses critérios. Ademais, apesar da fragilidade do 
ISSN 1981-3694

(DOI) $10.5902 / 198136947519$

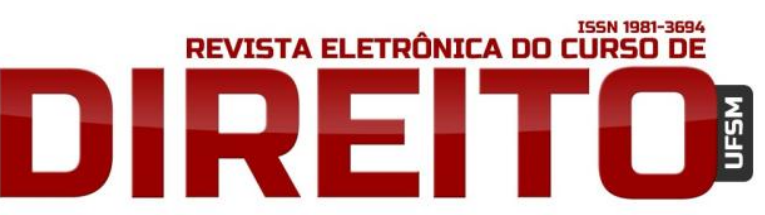

WEB 2.0: DESAFIO INSUPERÁVEL OU OPORTUNIDADE PARA A INCLUSÃO DIGITAL ?

conceito de "analfabetismo funcional", o índice se mantém estabilizado entre 2009 e 2011, e essa informação não aparece no site, que traz a informação durante o tempo otimista, de 2001 a 2009, o que também justifica o debate com foco no questionamento sobre a eficiência das políticas “inclusivas” atualmente utilizadas.

\section{REFERÊNCIAS}

ALMEIDA, Lilia Bilati; DE PAULA, Luiza Gonçalves. O Retrato da Exclusão Digital na Sociedade Brasileira. Revista de Gestão da Tecnologia e Sistemas de Informação, Volta Redonda, RJ, v. 2, n. 1, 2005, pp. 55-67. Disponível em <http://www.revistasusp.sibi.usp.br/scielo.php?pid=S180717752005000100005 \&script=sci_arttext>. Acesso em: 18 dez. 2012, p. 60

AYARA, Erm.; VIDOTTI, Sabg. Ambientes Informacionais Digitais. In Criação, proteção e uso legal de informação em ambientes da Word Wide Web. São Paulo: UNESP, 2010.

CASTELLS, Manuel. O poder da identidade. 5. ed. Tradução de Klauss Brandini Gerhardt. São Paulo: Paz e Terra, 2006, p. 374

DEMO, Pedro. Inclusão digital - cada vez mais no centro da inclusão social. Revista Inclusão Social, Brasília, v. 1, n. 1, p 36-38, out./mar., 2005. Disponível em

<http://revista.ibict.br/inclusao/index.php/inclusao/article/view/4>. Acesso em: 18 dez. 2012.

GONÇALVES, Victor Hugo. Inclusão digital como direito fundamental. 2011. 135 f. Dissertação (Mestrado em Direito) - Universidade de São Paulo, São Paulo, 2011, p. 35.

IBGE - Instituto Brasileiro de Geografia e Estatística. Pessoas de 5 anos ou mais de idade, por alfabetização. Disponível em <http://seriesestatisticas.ibge.gov.br/series.aspx?vcodigo= PD319\& $\mathrm{sv}=8 \mathrm{At}$ =pessoas-5-anos-mais-idade-alfabetizacao>. Acesso em $18 \mathrm{dez} .2012$

IBGE - Instituto Brasileiro de Geografia e Estatística. Taxa de analfabetismo funcional. Disponível em <http: //seriesestatisticas.ibge.gov.br/series.aspx?vcodigo=PD384\&t=taxa-analfabetismofuncional>. Acesso em $18 \mathrm{dez} .2012$

KLIX, Tatiana. Taxa de analfabetismo funcional fica estagnada entre 2009 e 2011. Último Segundo, São Paulo, 21 set. 2012. Disponível em < http://ultimosegundo.ig.com.br/educacao/2012-09-21/taxa-de-analfabetismo-funcional-ficaestagnada-entre-2009-e-2011.html>. Acesso em $18 \mathrm{dez} .2012$

LEVY, Pierre. O que é Virtual?. São Paulo, editora 34, 1996

MALAQUIAS, Bruno Pires. O Analfabetismo Digital. In: IBDI - Instituto Brasileiro de Direito da Informática. Disponível em <http://www.ibdi.org.br/site/artigos.php?id=159>. Acesso em: 18 dez. 2012. 
MANGINI, Jussara. Redes Sociais mais inclusivas. In: Agência FAPESP. Disponível em <http://agencia.fapesp.br/10806>. Acesso em: 18 dez. 2012.

MANTOVANI, Ana Margô, VIANNA, Cristiane de Carvalho. Construção Colaborativa de Ambiente de Aprendizagem com o uso de Wiki. In: Seminário de Informática - RS (SEMINFO RS'2008). Torres, 14 a 16 de novembro de 2008, 2008. Disponível em <http://www.seminfo.com.br/anais/2008/pdfs/seminfo/3-50748.pdf>. Acesso em : $18 \mathrm{dez}$. 2012, p. 1

MICHAELIS. Dicionário de Português On-line. Disponivel em <http://michaelis.uol. com.br/moderno/portugues/index.php?lingua=portugues-portugues\&palavra=analfabeto>. Acesso em: $18 \mathrm{dez} .2012$

O'REILLY, Tim. What Is Web 2.0. Design Patterns and Business Models for the Next Generation of Software. 30 set. 2005. Disponível em <http://oreilly.com/Web2/ archive/what-is-Web20.html>. Acesso em 18 dez. 2012.

RIBEIRO, Vera Masagão. Alfabetismo Funcional: Referências conceituais e metodológicas para a pesquisa. Revista Educação \& Sociedade, São Paulo, ano XVIII, n 60, dez. 1997. Disponível em <http://www.scielo.br/pdf/es/v18n60/v18n60a8.pdf>. Acesso em: 18 dez. 2012.

RODRIGUEZ, Carla Lopes, VALENTE, José Armando. Apropriação de Recursos Hipermidiáticos em Rede Social Inclusiva: elementos favoráveis à aprendizagem e à inclusão digital. Revista Digital La Educ@ción, n. 145, mai., 2011. Disponível em

<http://www.educoas.org/portal/La_Educacion_Digital/laeducacion_145/studies/EyEP_josevale nte_ES.pdf >. Acesso em: 18 dez. 2012

RONDELLI, Elizabeth. Quatro passo para a inclusão digital. Revista Sete Pontos, Rio de Janeiro, Ano 1, n. 5, 2003. Disponível em <http://www.comunicacao.pro.br/setepontos/5/4passos.htm>. Acesso em: 18 dez. 2012.

SORJ, Bernardo. Brasil@povo.com. A luta contra a desigualdade na Sociedade da Informação. Rio de Janeiro: Zahar, 2003, p. 58.

SORJ, Bernardo, GUEDES, Luiz Eduardo. Exclusão Digital. Problemas conceituais, evidências empíricas e políticas públicas. Revista Novos Estudos, n. 72, pp. 101-117, 2005, p. 102.

WIKIPEDIA, Web 2.0. Disponível em <http://pt.wikipedia.org/wiki/Web_2.0>. Acesso em: 18 dez. 2012.

WIKISPACES - Site para hospedagem gratuita de Wikis. Disponível em < http://www.wikispaces.com>. Acesso em: 18 dez. 2012.

Recebido em: 20.12.2012

Revisado em: 04.02.2013

Aprovado em: 26.02 .2013 